\title{
The morphosyntactic structure of number in Italian and Albanian. High and low plurals*
}

\author{
M. Rita Manzini \\ Università di Firenze \\ rmanzini@unifi.it
}

Received: April 14, 2020

Accepted: June 26, 2020

\begin{abstract}
I adopt the view that there are two number positions, including a lower Class position also hosting gender and a higher Num position. Italian $-a$ plurals and Albanian neuters are associated with a cluster of properties often thought to characterize low plurals: application to a restricted set of lexical bases, meaning idiosyncrasies, association with (feminine) gender and agreement in the singular with the finite verb. Current analyses associate count Ns (both singular and plural) with a specialized node while treating mass Ns as default. I argue that mass Ns are associated with a specialized feature [aggr] (Albanian neuter) - and that a divisibility feature [part] for plural can attach to both count and mass bases (Italian $-a$ ). The properties of low number depend on the properties of the Class position, including the fact that it is low enough to select gender and also to combine with a different Num, yielding mixed agreement.
\end{abstract}

Keywords: number; plural; mass; gender; neuter; agreement

Resum. L'estructura morfosintàctica del nombre en italià i albanès. Plurals alts i baixos

Adopto la postura que hi ha dues posicions per al nombre: una posició Classe baixa que també alberga el gènere i una posició Nombre més alta. Els plurals italians en - $a$ i els neutres albanesos s'associen a un cúmul de propietats que sovint es considera que caracteritzen els plurals baixos: l'aplicació a un conjunt restringit de bases lèxiques, els significats idiosincràtics, l'associació amb el gènere (femení) i la concordança en singular amb el verb finit. Les anàlisis actuals associen el Ns comptables (tant singulars com plurals) amb un node especialitzat mentre tracten els Ns de massa com a opció per defecte. Argumento que els Ns de massa estan associats amb una característica especialitzada [agreg] (el neutre albanès) i que hi ha un tret de divisibilitat [part] per al plural que pot adjuntar-se tant a bases comptables com de massa (l'italià -a). Les propietats del Nombre baix depenen de les propietats de la posició Classe, inclòs el fet que sigui prou baix per seleccionar el gènere i també per combinar-se amb un Nombre diferent, la qual cosa comporta una concordança mixta.

Paraules clau: nombre; plural; massa; gènere; neutre; concordança

* As I was exploring the net for the latest on Carme Picallo's work, I saw news of her passing away. I treasure her memory as my sometimes roommate in Cambridge, Mass. in the far away early 80 s. I would like to mark my appreciation for her intellectual and personal honesty and her strong commitment to principle, in science and in life. 


\section{Table of Contents}
1. Introduction
4. The Albanian neuter
2. Number positions and categories
5. Conclusions
3. Italian - $a$ plurals
References

\section{Introduction}

This article focusses on two case studies, involving plural in Italian and in Albanian. The Italian phenomenon, namely $-a$ plurals, is illustrated in (1). The masculine singular (1a) has both the regular masculine plural $-i$ with count interpretation (1b) and an $-a$ plural (1c) with mass interpretation and feminine gender. Therefore, the descriptive and theoretical challenge posed by $-a$ plurals concerns both their idiosyncratic interpretation and their idiosyncratic gender (cf. Acquaviva 2008).

(1) Italian
a. il cervello
the.MSG brain-MSG
'the brain'
b. $\mathrm{i}$ cervell-i
the.MPL brain-MPL
'the brains' (e.g. 'three brains')
c. l-e cervell-a
the-FPL brain-FPL
'the brains' (i.e. 'the brain, as foodstuff')

The Albanian phenomenon is the so-called neuter, i.e. a class of mass nouns displaying plural inflections and plural agreement with determiners and adjectival modifiers. These nouns nevertheless agree with the finite verb in the singular. The data in (2) are from conservative dialects of Italo-Albanian (Arbëresh), since neuters have become regular masculine singulars in standard Albanian (Camaj 1984).

(2) Arbëresh
a'ta $\operatorname{dia} \theta \quad$ oft to $\operatorname{mir}$
that.PL cheese is LKR.PL good
'That cheese is good'

Idiosyncratic meaning (mass/collective being salient), association with (feminine) gender, agreement with the verb in the singular are properties also associated with some classes of plurals in Afro-Asiatic languages. In the relevant literature (Larouchie \& Lampitelli 2015; Kramer 2016), these properties have been related to plural being merged in the same position as gender ( $n$, Class, etc), as opposed to the specialized Num position - i.e. to the existence of low as opposed to high plurals. Furthermore, singular agreement in the sentence as opposed to plural agreement in 
the DP, evokes the Agreement hierarchy of Corbett (1991) and Wechsler \& Zlatic's (2000) distinction between Concord features (relevant for DP-internal Agree) and Index features (relevant for sentential Agree). What is even more relevant for present purposes is that Landau (2015) proposes to reconstruct the opposition in terms of a configurationally lower Concord number (in $n$ ) and configurationally higher Index number (in Num/D).

I argue that both Italian - $a$ plurals and Albanian neuters are instances of low number, going beyond the "lexical plural" characterization for the $-a$ plurals provided by Acquaviva (2008), and the traditional neuter gender characterization of the Albanian data. As for Italian, the fact that the $-a$ class is masculine in the singular and feminine in the plural is a consequence of number being low enough that it can redetermine gender. Furthermore, Western Romance languages do not have the equivalent of - $a$ plurals, because they have high number ( $-s$ in Num). As for Albanian, I propose that mass is not a default, i.e. lack of $\mathrm{sg} / \mathrm{pl}$ features, but a primitive property [aggr], i.e. aggregate, represented in the low number position. The plural feature [part] is in turn compatible with [aggr] to the extent that it denotes divisibility. The plural agreement of determiners and modifiers tracks [part], the singular agreement of the finite verb tracks [aggr]. In essence, I defend many of the proposals on both Italian and Albanian advanced by Manzini \& Savoia (2018a, 2018 b), trying to better highlight their relation to different proposals present in the literature.

\section{Number positions and categories}

\subsection{The structure of $N(P)$}

The Indo-European $\mathrm{N}$ is standardly assumed to have a tripartite structure (Halle \& Vaux 1997; Calabrese 1998 for Latin and Romance). The root is followed by a thematic vowel reflecting inflectional class and gender, and by a morpheme externalizing number and/or case. Leaving aside case, which will not enter into the present discussion, a morphological schema along the lines of (3) is obtained. The category Class takes into account the conclusion that gender is the nominal classification system of Indo-European languages (Harris 1991).

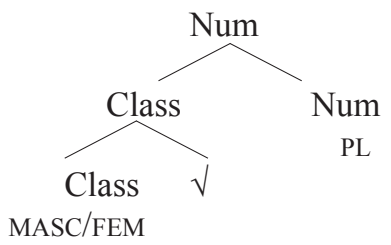

The structure in (3) is presented as a morphological word structure. In syntactic treatments, e.g. Picallo's (2008), it is usual to find that Class and Num (or their equivalent) are functional heads (orientated to the left), yielding a phrasal structure along the lines of (4). 
(4)

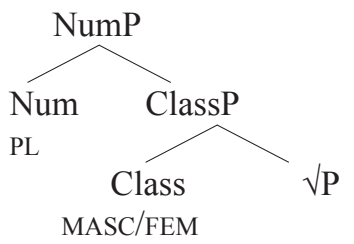

There are several standardized syntactic models for mapping (4) to (3). The earliest one is head movement/incorporation (Baker 1988) - namely movement of the lexical base to the closest functional head and incorporation of the former to the latter. This operation results in the morphology mirroring the syntax. Chomsky (2001) argues that head movement countervenes several restrictions observed by other types of movement (e.g c-command) and cannot therefore be unified with them. An alternative is proposed by Chomsky (1995), namely that words are generated in the lexicon and inserted into syntactic derivation, as in classical lexicalist approaches. The process of matching word structure to syntactic structure is a process of feature checking (Agree). The limit of this solution is that the same structure is replicated twice once as word structure and once as syntactic structure.

Brody (2000), having noted this redundancy, proposes that there is a single syntactic structure where "a single copy of lexical item can serve both as a head and as a phrase". To understand his point, it is useful to write (3)-(4) in his notation, namely (5). (5) is both a phrase structure tree and a word tree. The Mirror Principle governs the equivalence between the phrase-level and the word-level structure, insuring that the syntactic relation ' $\mathrm{X}$ complement of $\mathrm{Y}$ ' is linearized as the morphological sequence Y-X, e.g. Class-Num.

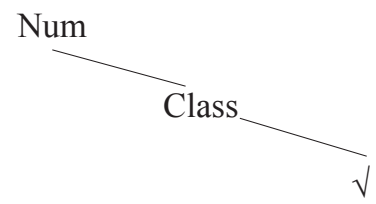

Whichever model one chooses, the important point is that syntax is sufficient to construct word structure, and vice versa. I will use word structures like (3). However, any of the algorithms mentioned (head movement, feature checking, Mirror Theory) can map these structures to phrasal syntax and vice versa. The reason I prefer using word structures is simply one of expedience, given that eventual phrasal Specs of ClassP, NumP etc. are not considered here. ${ }^{1}$

Some clarification is in order concerning the labels in (3). Many authors (e.g. Kramer 2015) identify the node hosting gender/nominal class with Marantz's (1997) nominalizing category $n$. Roots are taken to lack a category and therefore

1. I do not assume postsyntactic (so-called Late) vocabulary insertion (unlike Distributed Morphology, DM, Halle \& Marantz 1993), and therefore syntax is projected from the actual lexicon (not some abstract lexicon), as in classical lexicalist approaches (including Chomsky 1995). 
need to be categorized by merging with appropriate nominalizing material. The intuition is that a root turns into what we call $\mathrm{N}$ insofar as it is slotted into a classification system of some sort, whence the identification of gender/nominal class with $n$. Other authors however separate $n$ from nominal class (e.g. Déchaine et al. 2014, who has nominal Asp categories). For present purposes, given that roots are not the objects of the present discussion, I will simply assume that an $\mathrm{N}$ stem is merged with Class, as in (6). Constituents are labelled by $\mathrm{N}$ and by the $\varphi$-features merged with $\mathrm{N}$, namely Class and Num.

(6)

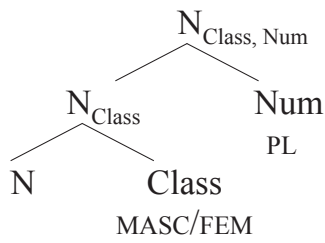

Another complication concerning Indo-European languages arises from the fact that their so-called thematic vowels (e.g. in Spanish, Latin) do not reflect simply gender, but rather an intersection of gender (nominal class) and inflectional class. A well-known treatment of thematic vowels is proposed by Oltra-Massuet \& Arregi (2005). In essence, these authors propose that a Th node is adjoined to Class $/ n$ postsyntactically. The content of Th are diacritics such as [I] for I inflectional class, etc. and the latter are in turn spelled out as, say, -o in Spanish, etc. The fact that Th is merged post-syntactically automatically explains why inflectional class does not participate in Agree relations, assuming Agree to be syntactic. In order to avoid recourse to a post-syntactic component, I adjoin the thematic vowel to Class in the syntax, as in (7). I call this node Infl to mark its different status with respect to Th. I formalize the fact that inflectional class does not enter into Agree by assuming that it does not project, unlike Class and Num. ${ }^{2}$

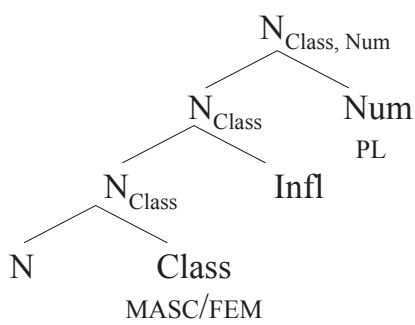

2. Nothing much changes in other respects. The rule that inserts the inflectional class diacritics, e.g. [I], [II], [III] in Spanish, under Th is sensitive to the context determined by certain sets of roots. Similarly, in present terms, a particular realization of Infl selects a class of (gendered) roots/lexical bases, essentially as in Kayne (2010: 73-74). Selectional mechanisms are also responsible for the pairing of roots/lexical bases with gender (other than natural gender). 
The final set of assumptions that I need to make explicit concerns the merger of two words, say N in (7) and D. Ds, no less than Ns, can be morphologically complex. For instance, in many Romance languages, Ds have exactly the same internal structure as Ns, including a D lexical base denoting deixis/quantification, a gender and inflectional class vowel and eventually a number specification, as in (8).

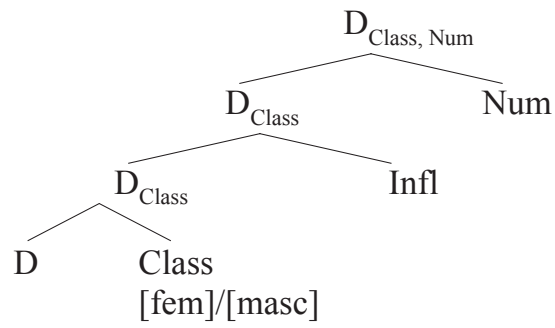

DPs of the elementary form [D N(P)] depend on merging the word trees in (7) and (8). The result of this merger are structures like (9). The Class and Num properties are visible at the root nodes N and D. Agree, i.e. Minimal Search and Match applies between D to N, under Minimality and the Phase Impenetrability Condition, as indicated by Chomsky (2000). ${ }^{3}$

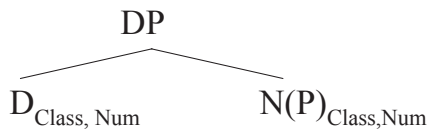

\subsection{Number positions}

Wiltschko (2008) is a notable example of a series of works arguing for a layered view of plural, under which English realizes the dedicated Num position, but in Halkomelen Salish, number is represented in a lower position, adjoined to the root. More relevant for present purposes, several scholars conclude that in AfroAsiatic languages, number can distribute between the Num dedicated position and the position otherwise taken by gender, namely Class $/ n$, as schematized in (10) (Lecarme 2002 for number in $n$ in Somali; Larouchie \& Lampitelli 2015 on Arabic and Somali; Kramer 2016 on Amharic).

3. Given that D c-commands N, one expects D to act as probe and N as goal (Carstens 2000). However the uninterpretable/unvalued status of the $\varphi$-features of D as a probe are not without problems (Danon 2010). Manzini \& Savoia (2018a) propose that at least within DP, probe-goal pairs are defined solely by the c-command relation, while all feature sets are equally interpretable/valued on $\mathrm{N}$ and on its functional categories, including D. Agree therefore does not delete uninterpretable features or value unvalued ones. It creates equivalence classes of occurrences of non-distinct $\varphi$-feature sets corresponding to a single argument. 
(10)

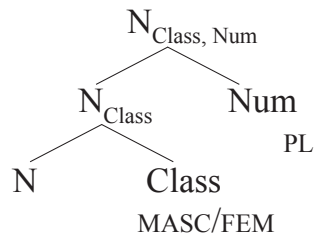
$\leftarrow \quad$ PL

There are prima facie reasons to believe that the same layering is present in Romance. In languages like Spanish, the dedicated $-s$ plural morphology externalizing Num is added to the inflectional class vowel, as in (11b). However, in languages like Italian (11a), vocalic inflections alternate according to both gender and number, inviting the conclusion that plural is associated with the lower Class position and therefore externalized together with gender. Furthermore, the two plural morphologies (namely the vocalic plural of Italian and the $-s$ plural of Spanish) can combine, as in Friulian (11c) (Bonet 2018; Savoia et al. 2018).
(11) a. ragazz-o 'kid-M'
a'. ragazz-i 'kid- PL
Italian
b. niñ-o 'child-M'
b'. niñ-o-s 'child- M-PL' Spanish
c. femin-a 'woman-FSG'
c'. femin-i-s 'woman-PL-PL' Friulian

Let me provide some sample representations. A Spanish paradigm like (12a) is captured by the tree in (12b). The vocalic inflections reflect gender and inflectional class, while the specialized $-s$ segment for plurality occurs in Num.
niñ-o
'child-M, boy'
a'. niñ-o-s
'child-M-PL, boys'
niñ-a
'child-F, girl'
b'. niñ-a-s
'child-F-PL, girls'

b.

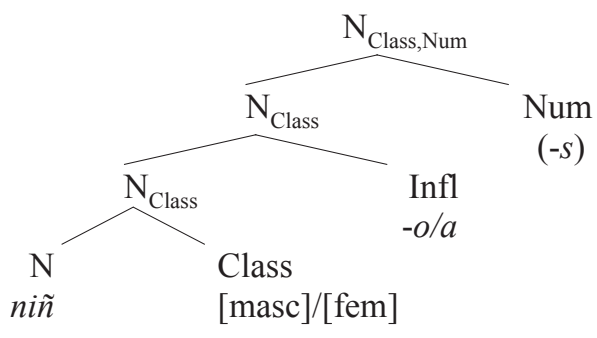

In Italian (13a), the inflectional vowel is sensitive to gender and inflectional class specifications, as in Spanish. However, plurals are not obtained by adding specialized Num morphology, but rather by having recourse to a different vocalic inflection. This points to plural being represented in Class together with gender - and therefore externalized together with gender in Infl. This analysis is summarized in (13b). 
(13)
ragazz-o 'kid-M, boy'
a'. ragazz-i
'kid-MPL, boys'
ragazz-a 'kid-F, girl'
b'. ragazz-e
'kid-FPL, girls'

b.

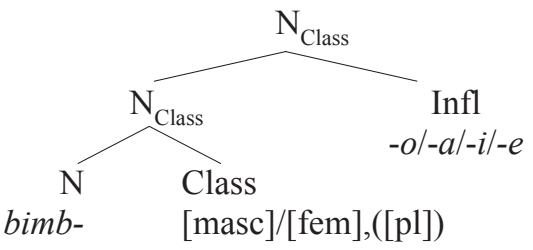

In (13b), number and gender are not ordered with respect to one another under the node Class. When [pl] is present, $(13 \mathrm{~b})$ is then in principle ambiguous between (14) and (15). In (14) gender features selected by the lexical base are merged with it first, while number specification is added on top of them. In (15) the reverse order is present. The iteration of the Class node in (14)-(15) is nothing new. For instance, Déchaine et al. (2014) deal with the fact that nominal class morphology in Bantu (specifically Shona) can be stacked by iterating what they call nominal Asp. At present, no evidence chooses between (14) and (15); I return to this question in section 3.
$\left[_{\text {Class }}\left[_{\text {Class }}\right.\right.$ bimb-
masc/fem]
$\mathrm{pl}]$
(15) $\left[_{\text {Class }}\left[_{\text {Class }}\right.\right.$ bimb-
$\mathrm{pl}]$
mase/fem]

Going back to (12b) and (13b), it ought to be possible to find a language, where number may be expressed both by Class/Infl and by the specialized Num node. Indeed in Friulian varieties (11c), the $-i$ plural of Italian combines with the $-s$ plural of Western Romance, yielding structures like (16). The combination of two plural morphologies in (16) is an argument in favour of the double position for plural and indirectly of the analysis of Italian-style plurals in (13b). ${ }^{4}$

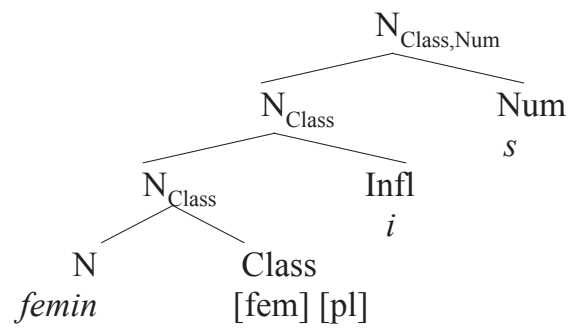

4. In the discussion of double number configurations of Arabic, Fassi Fehri (2018) argues that the two instances of number are differently interpreted. For instance + unit applied to a mass term works as a singulative, creating a count singular from it. More relevantly for present purposes, Fassi Fehri assumes the +unit can apply to a plural - creating a plurative, namely essentially a collective N. However, this is not a necessary state of affairs, even in the Afro-Asiatic family. Kramer (2016) states explicitly that in Amharic the doubling of low and high plural may return the same meaning as a single plural. In this latter case, the two occurrences of plural may be seen as instantiating the same plural feature, i.e. as an instance of doubling. 
While Spanish has a long history of treatments in formal grammars (dating back at least to Harris 1991), the Italian $\mathrm{N}$ is less often considered in the literature. Ferrari Bridgers (2008) concentrates on gender and its association with $n$. More recent work by Kučerová (2018) again concerns gender and gender agreement; however, in her sketch of Italian $\mathrm{N}$ structure she associates number with the same $n$ slot as Class. In this respect, therefore, there is broad compatibility with the present work.

On the other hand, Lampitelli (2014) argues that Italian plurals have a structure similar to that of Spanish, though gender $(n)$ and number (Num) are lexicalized by phonological elements, in the sense of Government Phonology. For instance, feminine plural $-e$ is the effect of the phonological combination of gender morphology -A with number morphology -I. In other words, the phonological derivation replays the historical origin of Italian -e from Latin -ae /ai/ (Halle and Vaux 1998). However, Lampitelli's analysis does not cover the evidence from Friulian (16), since both $-\mathrm{I}$ (i.e. $-i$ ) and $-s$ ought to be in Num.

For Friulian, Bonet (2018: 19) suggests a different approach, namely that "the vowel $-i$ that appears in the plural is also an allomorph of [feminine] which surfaces only in the context of [plural]". The same approach could be generalized to Italian. Thus [pl] feature would be generated in Num, albeit not pronounced, and determine the $-i /-e$ allomorphs in (13b). This would mean that there is no need of a [pl] feature in Class.

Now, the properties of Italian - $a$ plurals briefly reviewed in relation to (1), namely application to a restricted set of lexical bases, idiosyncratic meaning and association with gender, independently characterize low plurals, i.e. plurals in $n$ /Class, in AfroAsiatic languages (Kramer 2016; Larouchie \& Lampitelli 2015). Other properties characterizing low plurals include agreement in the singular, as in (17). All of these are possible, not necessary properties; high plurals on the other hand exclude them.

(17) Properties of low/Class plurals
a. Partial productivity/selection
b. Semantic idiosyncrasies
c. Selection of gender
d. Agreement in the singular

In present terms, the fact that $-a$ plurals display at least some of the properties in (17) is a consequence of the fact that they are low plurals - as are all Italian plurals. ${ }^{5}$ Languages like Spanish which only have high plurals are predicted to have no plural class comparable to - $a$ plurals. This prediction is not available under Bonet's (2018) proposal. I return to this line of argument in section 3.

5. Even in Afro-Asiatic languages, many low plurals (while attaching to a lexically restricted set of bases) have perfectly regular meaning, regular gender and plural agreement (e.g. Kramer 2016). Therefore the fact that many Italian plurals have perfectly regular meaning and agreement is not necessarily an obstacle to their low treatment. 


\subsection{Number categories}

Turning briefly to interpretation, I follow Higginbotham (1985) in assuming that the lexical base is a predicate (a property) with an open argument that is ultimately satisfied by D. I take genders to be predicates in turn, further restricting the argument open at the root (Percus 2011). For instance, the Italian root for 'kid' is compatible with both masculine and feminine specifications, yielding the paradigm in (13a), where gender (interpreted as natural gender) and the animate root intersectively define the referent. At the same time, for so-called arbitrary gender, the assumption generally is that it is not interpreted, more or less like inflectional class. According to Manzini \& Savoia (2019), however, arbitrary gender is not uninterpretable - just not compositionally interpretable. In other words, arbitrary gender is interpreted as an idiom of sorts. This hypothesis allows me to avoid uninterpretable gender features (Kramer 2015), and for this reason, it is adopted here. ${ }^{6}$

Let us then turn to number, which represents the focus of the present discussion. Plural is interpreted as adding the divisibility property to the lexical base. This divisibility property is shared with mass nouns, and opposes plurals and mass nouns to atomic singulars, along the lines of (18a). Nevertheless, best known morphological systems, e.g. English, contrast count plurals with singular mass and atomic Ns, along the lines of (18b).
a. divisible (set \& mass)
vs
atomic
b. divisible set
vs mass \& atomic

A standard syntactic representation of number semantics is that offered by Borer (2005), Chierchia (2010). For Chierchia, plurals and atomic singulars as represented by a sg/pl feature in At(om)P. In Chierchia's terms, the singular number of mass nouns is a "semantically void" default (Chierchia 2010: 134-136), as in (19). This is essentially the same syntax proposed by Borer (2005), who calls the number node DivP.

\section{(19) AtP/DivP: sg/pl \\ default: mass}

Now, the system in (19) is built to predict that plurality only applies to count terms while mass status coincides with the default singular, as is normally the case in English. However, plurals may be deployed to denote any divisible entity, whether count or mass. For instance, Italian has mass plurals logically equivalent to the singular, as in (20). Therefore, singular and plural cross-cut with the mass/ count distinction, making systems of the type in (19) ultimately insufficient in mapping semantic primitives of number to number syntax (cf. Tsoulas 2009 on Greek; Fassi Fehri 2012 on Arabic).

6. Recall that uninterpretable features in syntax need to be checked by their interpretable counterparts. This can be disregarded by Kramer (2015) only because she works within a DM morphological component. 
(20) a. l' acqua piovana/ le acque piovane

the water-FSG rain-ADJ-FSG/ the-FPL water-FPL rain-ADJ-FPL

'the rainwater(s)'

b. il mare/ i mari del Sud the sea-MSG/ the-MPL sea-MPL of.the South 'the South Sea(s)'

While the system in (19) uses a single category and effectively a single feature (sg/pl), other systems use at least two features/categories. The classical system of Rijkhoff (1991) has [structure] for divisibility and [shape] for individuation. In the syntactic formalization of Arsenjievic $(2006,2016)$, the category Part[itive] characterizes both count plurals and mass terms. On the other hand, count plurals have a PartP structure hosting specifications in its Spec capable of valuing it as atomic, as in (21). Mass terms host no such specifications and are therefore defaults in this respect. Again, this system, as far as I can tell, has no way of representing a mass plural.

(21) Count: unit of partition defined in SpecPartP

Mass: no unit of partition defined in SpecPartP

Manzini \& Savoia $(2018 b, 2019)$ argue in favour of a syntactic representation of number where mass status is associated a feature [aggr]. They refer to Chierchia (2010: 120) for the term aggregate: "some sums will be the sums of stable individuals... Others are not; they are the sums of unstable individuals. This type of 'partial sums' $\left(\mathrm{P} \Sigma_{\mathrm{c}}(\mathrm{U})\right)$ lend themselves naturally to the modelling of mass nouns (reflecting the idea that the latter are aggregates whose components are unknown)". Their proposal denies that mass terms are a default at any level of structuring. Specifically, they argue that the feature [aggr] on its own defines the so-called Romance neutro de materia, i.e. an inflectional class including only mass nouns. Atomic singulars result from the lack of number classification, i.e. they are the defaults. As indicated in (22), Manzini and Savoia further use the feature $[\subseteq]$ to depict plurality, in the sense of divisibility: $[\subseteq]$ alone is set divisibility, i.e. count plurality. If [aggr] combines with [ᄃ], it yields mass plurals - which for Manzini \& Savoia (2018b, 2019) include - $a$ plurals. The problem however is that - $a$ plurals are not necessarily mass plurals; they can be perfectly regular count plurals.

\section{(22) [aggr] mass \\ $[\subseteq] \quad$ plural \\ $[\operatorname{aggr}][\subseteq] \quad$ mass plural}

The relation between mass and plurals is one of the main topics of sections 3-4. The other main topic is the idea that number specifications can be merged either as part of Class ( or $n$ ) node or as a specialized Num node. Interpretively, the layered picture of number corresponds to the fact that number interfaces with at least two 
different sets of properties of natural languages. On the one hand, number is part of the classification system of natural languages (Class), especially through the mass/count distinction. On the other hand, number affects the interfacing of the DP with the event - for instance, multiple participants may also imply a multiplicity of events. In this interfacing role between event and event participants, number (Num) is then more like case. ${ }^{7}$

\section{Italian - $a$ plurals}

\subsection{Data and previous literature}

Italian - $a$ plurals have both limited productivity and idiosyncratic meaning. Specifically, they include mass or mass-like (collective) plurals, formed on the basis of atomic singulars, as in (23); - $a$ plurals are on the left, singulars on the right.

(23)

$\begin{array}{llll}\text { mur-a } & \text { '(e.g. city) walls' } & \text { mur-o } & \text { 'wall' } \\ \text { cervell-a } & \text { 'brains (e.g. foodstuff)' } & \text { cervell-o } & \text { 'brain' } \\ \text { fondament-a } & \text { 'foundations' } & \text { fundament-o } & \text { 'foundation' } \\ \text { budell-a } & \text { 'guts' } & \text { budell-o } & \text { 'gut' }\end{array}$

Other $-a$ plurals are count plurals, denoting body parts (24a), artifacts (24b), events (24c), foodstuffs (24d), numerical sizes (24e). In some Center-South Italian varieties $-a$ plurals are more productive than in standard Italian, but the same semantic classes are involved.

\begin{tabular}{|c|c|c|c|}
\hline bracci-a & 'arms' & bracci-o & 'arm' \\
\hline cigli-a/sopraccigli-a & 'eyelashes/eyebrows' & (soprac)cigli-o & 'eyelash/brow' \\
\hline dit-a & 'fingers' & dit-o & 'finger' \\
\hline ginocchi-a & 'knees' & ginocchi-o & 'knee' \\
\hline labbr-a & 'lips’ & labbr-o & 'lip’ \\
\hline oss-a & 'bones' & Oss-o & 'bone' \\
\hline lenzuol-a & 'sheets' & lenzuol-o & 'sheet' \\
\hline url-a & 'shouts' & url-o & 'shout' \\
\hline uov-a & 'eggs' & uov-o & 'egg' \\
\hline centinai-a & 'hundreds' & centinai-o & 'about a hundred' \\
\hline migliai-a & 'thousands' & migliai-o & 'about a thousand' \\
\hline migli-a & 'miles' & migli-o & 'mile' \\
\hline pai-a & 'pairs' & pai-o & 'pair' \\
\hline
\end{tabular}

7. Though case is not discussed here, number and case seem to share the same slot Num/K at least in Indo-European languages (Halle \& Vaux 1998). 
In fact, $-a$ plurals often have a regular $-i$ plural counterparts. In several instances, the $-i$ plural has a distinct meaning with respect to the $-a$ plural, for instance in (25). Specifically, where the - $a$ plural is mass(-like), the $-i$ plural is always a count plural. However in other instances the two plurals appear to have equivalent meaning, leading Thornton (2010-11) to use the morphological category of overabundance, e.g. (26).

\begin{tabular}{|c|c|c|c|}
\hline (25) mur-o & 'wall' & mur-i & 'walls (except city walls)' \\
\hline cervell-o & 'brain' & cervell-i & 'brains' \\
\hline oss-o & 'bone' & oss- $\mathrm{i}$ & ‘bones' (e.g. ham bones) \\
\hline bracci-o & ‘arm’ & bracc-i & 'arms (except bodypart, e.g. crane arms) \\
\hline hi-o & lee' & occh-i & 'knees' \\
\hline
\end{tabular}

The other important property of - $a$ plurals is their interaction with gender. All of the singular Ns listed in (23)-(24) are masculine, and so are the $-i$ plurals in (25)-(26). However, - $a$ plurals are feminine, not masculine, as can be seen from the agreement patterns in (27). Therefore, $-a$ plurals determine their own feminine gender, independently of the masculine gender of their lexical base.

$$
\begin{aligned}
& \text { (27) a. il bel bracci-o } \\
& \text { the-MSG nice-MSG arm-MSG } \\
& \text { b. 1-e bell-e bracci-a } \\
& \text { the-FPL nice-FPL arm-'A' }
\end{aligned}
$$

The semantic and syntactic idiosyncrasies associated with - $a$ plurals have received some attention in the formal literature, starting with Acquaviva (2008). Obviously, $-a$ plurals have the same root as their $-o$ or $-i$ plural counterparts in (23)-(26). However, Acquaviva (2008: 157-158) argues that they are distinct lexical items. In other words, $-a$ plurals are a piece of derivational morphology (a "lexical plural" in his terms). He justifies his conclusions empirically, by means of tests like for example (28); in (28) uova 'eggs' is a -a plural, but l'una/l'uno 'each' agrees in the singular. Acquaviva reasons that in this kind of example, if - $a$ plurals were just the product of inflecting - $o$ singulars, then the masculine gender of the lexical base ought to be accessible, triggering masculine singular agreement. His data indicate that only agreement of each in the feminine singular is possible.

(28) le uova costano 20 centesimi l'una/ l'uno
the-FPL egg-'A' cost 20 cents each-FSG/ each-MSG
'The eggs cost 20 cents each'

According to Loporcaro \& Paciaroni (2011), however, for many speakers both feminine and masculine agreement are possible in (28); Manzini \& Savoia (2018b, 2019) agree with the less restrictive judgement. Loporcaro and Paciaroni also widen their discussion from standard Italian to Center-South Italian varieties 
where $-a$ plurals are more productive, i.e. they involve a larger class of lexical bases, finding that overall, native judgements do not support Acquaviva's prediction.

Italian varieties like that in (29)-(30) also suggest a different line of argument. The semantic class of 'finger(s)', 'arm(s)' etc. belongs to the masculine - $u$ class in the singular and can display an $-e$ feminine inflection in the plural, cf. (29a-b). The lexical bases involved and the switch from masculine to feminine are the same as in Italian - $a$ plurals; the example in (29c) also shows that there is a regular plural morphology for $-u$ singulars, namely $-i$, again as in Italian. Contrary to Italian, however, the $-e$ plural in (29a-b) is the regular feminine plural also seen in $(29 d)$.

$\begin{array}{rlr}\text { (29) a. } & \text { l-u } & \text { ðit-u } \\ \text { the-MSG } & \text { finger-MSG } \\ \text { b. } & \text { l-u } & \text { vratt5-u } \\ & \text { the-MSG } & \text { arm-MSG } \\ \text { c. } & 1-u & \text { kortell-u } \\ \text { the-MSG } & \text { knife-MSG } \\ \text { d. } & \text { l-a } & \text { recc-a } \\ \text { the-FSG } & \text { ear-FSG }\end{array}$

$$
\begin{array}{ll}
\text { l-e } & \text { ðet-e } \\
\text { the-FPL } & \text { finger-FPL }
\end{array}
$$$$
\text { l-e vratt } \int \text {-e }
$$$$
\text { the-FPL arm-FPL }
$$$$
\text { 1-i kurtell-i }
$$$$
\text { the-MPL knife-MPL }
$$$$
\text { l-e recc-e }
$$$$
\text { the-FPL arm-FPL }
$$

Monte Giberto (Fermo, Marche)

If Acquaviva's conclusions are extended from Italian to the variety in (29), we need to assume that there are two -e morphemes, which have the same feminine plural properties, except that one is inflectional, namely (29d), while the other depends on a derivational process, namely (29a-b). The conclusion is not the simplest one available, namely that $-e$ is the feminine plural inflection throughout. Another line of argument is that pursued by Thornton (2010-11) in relation to overabundant plurals like (26). The complete equivalence of $-a$ and $-i$ plurals is hard to reconcile with a different status (derivational vs. inflectional).

Henceforth, I will assume that $-a$ plurals are inflectional. Loporcaro \& Paciaroni (2011), whose framework is historical-typological rather than formal, propose that languages like Italian or the Monte Giberto variety have not just the traditional genders (masculine, feminine and eventually neuter), but also an additional gender, defined by the alternation of masculine in the singular and feminine in the plural, namely what they call a genus alternans (alternating gender). Manzini \& Savoia $(2017,2018 b)$ however provide evidence that gender switch is not a necessary correlate of $-a$ plurals. They show that $-a$ plurals are found in Calabrian varieties where masculine and feminine gender are distinct only in the singular (not illustrated here). Furthermore, while it is true that the vast majority of - $a$ plurals have masculine singular counterparts, $-a$ plurals can also be formed from feminine singular bases as in the variety in (30). 
$\begin{array}{ll}\text { (30) ojn-a/ } & \text { ojn-a } \\ \text { nail-FSG/ } & \text { nail-FPL }\end{array}$

Guardiaregia (Campobasso, Molise)

I therefore conclude that - $a$ plurals do not depend on gender. They are a number phenomenon, with gender switch (to the feminine) as a possible byproduct, not a necessary one.

\subsection{Analysis}

At this point, we are left essentially with the proposal that $-a$ plurals are a type of inflectional plural. What we need is a way of representing the ambiguous, or indeterminate, status of - $a$ plurals between regular count readings, e.g. (24), and mass(-like) readings, e.g. (23). I take it that the fact that the property of divisibility is shared by count plurals and mass terms is part of the answer. Manzini \& Savoia (2018a) call the relevant property $[\subseteq]$. In their conception, $[\subseteq]$ is a partition (part/ whole, inclusion, etc.) predicate realized by plurals at word level, but also responsible for genitive/dative case when applied in phrasal syntax. ${ }^{8}$ I keep their conception. However, I relabel the relevant feature [part], so as not to induce confusion with the subset relation. Its basic interpretation is divisibility when applied to nominal bases and its realization (in Italian, English etc.) is plural, as in (31).

(31) [part]: SEM: divisibility, ambiguous between subset and mass PHON: plural

Based on (31), both cervella 'brains' in (23) and dita 'fingers' in (24) have the structure in (32). With cervella 'brains', the plural morphology acts as a massifier, though dita 'fingers' is an ordinary count plural.

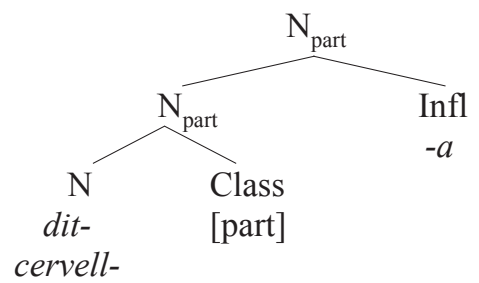

Since the number specifications in (32) are associated with the Class node, i.e. - $a$ plurals are low plurals, we expect that they can display the properties independently connected with low plurals by the literature on Afro-Asiatic languages. Indeed, they are associated with a restricted number of lexical bases and with interpretive idiosyncrasies, and they select their own feminine gender, superseding

8. Manzini \& Savoia (2018a) explain in this way the fact that plural (direct case) is often syncretic with oblique (singular) in Indo-European languages. 
the masculine gender normally selected by the root. I interpret the gender facts in a fairly obvious way. The [part] number attaches to the root early enough that the gender is determined by the root plus its number properties. Hence I add [fem] to the number properties of the Class node in (32), as in (33).

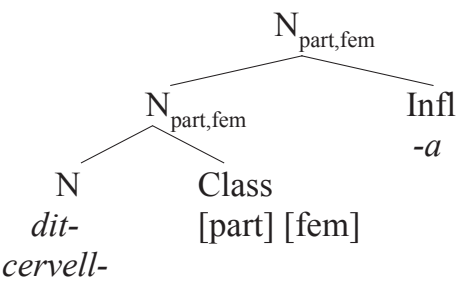

A different matter is how the feminine gender supersedes the masculine gender selected by the root in the singular. An account that immediately comes to mind is to invoke the markedness of feminine gender and the default nature of masculine. This kind of proposal for the Romance languages (Spanish) dates back at least to Harris (1991). Thus, the only gender is [fem]; [masc] is just the absence of gender. Technically, the [fem] feature in (33) does not overwrite a [masc] gender, but simply introduces a specified gender where no gender is otherwise specified.

An alternative solution is that number is merged even lower than gender. Following the discussion of (14)-(15) above, a structure like (33) may be understood as a shorthand for (34a), where [fem] is selected by the constituent formed by the lexical base and by [part]. Thus, the lexical base does not directly select its gender; rather it is the pluralized based that selects gender. This may be contrasted with a structure like (34b) for regular - $i$ plurals; in (34b) gender is selected by the lexical base and number is added on top.

(34) a.

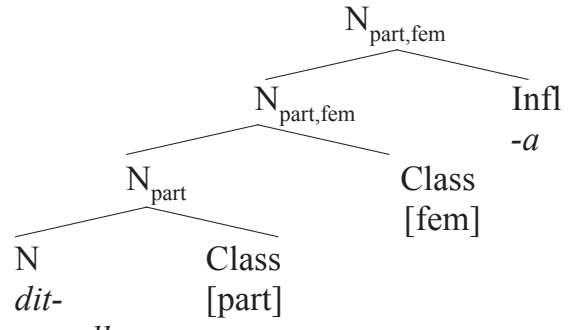

cervell-

b.

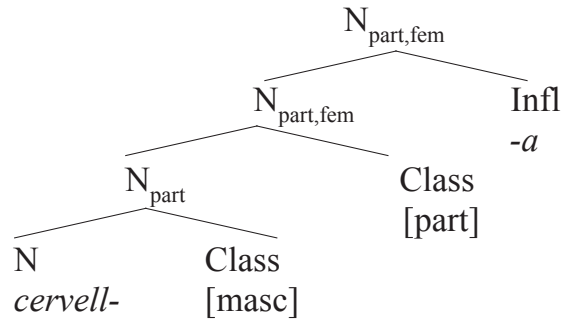


The structure proposed in (34a) can be used as a basis for understanding the other properties of $-a$ plurals, namely selection of a small set of lexical bases (many of which also have the regular $-i$ masculine plural) and meaning idiosyncrasies. The fact that the meaning of $-a$ plurals is not necessarily predictable from the meaning of the lexical base and the meaning of [part], i.e. it is not compositional, can be tentatively understood by assuming that the immediate merger of a lexical base with [part] is a possible idiom.

As it turns out, one of the Ns chosen for the examples in (32)-(34), namely dita 'fingers' has a perfectly predictable count meaning as does uova 'eggs' and the other few lexical bases which only have - $a$ plurals, including measures (miglia 'miles' etc.). In most instances, however, the same lexical bases occur both with an - $a$ plural and with a masculine $-i$ plural. Cases like cervella/cervelli 'brains', also illustrated in (32)-(34) are particularly clear. While (34a) has an idiom interpretation (it means 'brains as foodstuff', mass plural), the $-i$ plural is the regular count plural of 'brain' not only morphologically, but also interpretively, encompassing literal meaning, metonymic meanings etc.

Independently of whether we adopt (33) or (34), the relevant features for Agree, present on $\mathrm{N}$, are [part] and [fem] - so that agreement is in the feminine plural. As we also expect, finite verbs agree in the plural; perfect participles agree in feminine plural - as illustrated in (35a). For instance the structure for Agree between $\mathrm{N}$ and $\mathrm{D}$ is as in (35b).

$$
\begin{aligned}
& \text { Le dita si sono rotte } \\
& \text { the-FPL finger-APL REFL be-PL broken-FPL } \\
& \text { 'The fingers got broken' }
\end{aligned}
$$

b.

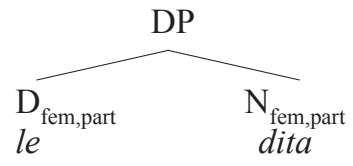

Let us summarize so far. The present analysis of Italian rests on the following proposals: (i) plural is represented in the Class node; (ii) plural may be selected by certain lexical bases with an idiomatic meaning; (iii) the constituent formed by a lexical base and a number may select a gender (different from that slected by the lexical base on its own). Specifically as an instance of (ii) we have examined the case in which an atomic base ('brain') combined with [part] returns a mass meaning. The idiosyncrasy in this instance is clear, since an atomic base is expected to yield an atomic plural and a mass base a mass plural. An atomic base returning a mass meaning under pluralization is a sort of low-level idiom.

At this point of the discussion, the question can perhaps be raised whether we haven't come back full circle to the lexical plural analysis of Acquaviva (2008). Nobody denies that in the presence of partial productivity and idiomatic meanings, lexical restrictions play a role. However $-a$ plurals are structured by the inflectional categories of number and gender. Alternatively, we may agree to dismiss the derivation/inflection opposition. What matters is that the kind of affixal heads 
that we are considering are low enough in the word to be heavily conditioned by lexical selection but high enough to enter into the determination of the syntactically relevant $\varphi$-feature set. ${ }^{9}$

\subsection{A crosslinguistic comparison}

By hypothesis, association with the Class node is a general property of vocalic plurals in Italian, not just a property of - $a$ plurals. A possible problem is raised by the fact that while all plurals in Italian are low plurals, only the small $-a$ subclass displays special syntactic and semantic characteristics. However, under the analysis in (34), gender selection is connected to the fact that number is merged directly with the lexical base; direct merge with the lexical base further allows idiomatic meanings.

More importantly, we predict that there are no Romance languages with high plurals (i.e. plurals in Num), which have a subclass of plurals comparable with Italian - $a$ plurals. A relevant set of data is provided by Sursilvan (Romansh) varieties. In Sursilvan, as reported by Manzini \& Savoia (2017), the masculine singular $\mathrm{N}$ max 'apple' in (36a) has the regular $-s$ count plural mail-ts 'apples' in (36b). The mass-like/collective interpretation that is sometimes associated with $-a$ plurals in Italian is also available in Sursilvan, but it is associated with the feminine singular $\mathrm{N}$ mail- $a$ 'apple set' in (37). The alternation in (36)-(37) is partially productive in Sursilvan and it involves a lexical class compatible with that of Italian - $a$ plurals, including notably body parts (Sursilvan bratf- $a$ 'arm set', det- $a$ 'finger set') and food items (Sursilvan per- $a$ 'pear set'). ${ }^{10}$

(36) a. in $\operatorname{ma} \kappa$

a.MSG apple

b. kwel-s mail-ts ai-n marf-s

that-PL apple-PL be-3PL rotten-PL

'Those apples are rotten'

(37) $K$-a mail-a ai marf-a

the-FSG apple-FSG be.3SG rotten-FSG

'The apples are rotten'

Vattiz (Lumnezia, Switzerland)

9. Savoia et al. (2017) conclude much the same for evaluative morphology in Italian. Evaluatives are fully productive as size classifiers; at the same time, diminutives and augmentatives can form Ns from verbal bases and diminutives can form count Ns from mass bases (i.e. they are singulative affixes). In all uses, evaluatives can introduce their own gender. Note however that deverbal nominalization ought to be derivational; size classification and singulatives are inflection-like.

10. Both the Italian and the Sursilvan phenomenon are historically connected to the Latin $-a$ neuter plural (e.g. brachi-a 'arms'). 
Sursilvan (37) is accounted for by Manzini \& Savoia (2017) in terms of the feature [aggr], merged in Class and triggering a gender shift. The point here is neither the illustration of Sursilvan nor its analysis - but rather the fact that Sursilvan provides some sort of minimal pair with Italian. Both languages have a partially productive class of mass-like/collective nouns (body parts, food items etc.) obtained by inflectional means. In both languages the relevant lexical bases have a regular atomic singular and a regular count plural which are masculine - while the masslike/collective meaning involves feminine gender. The difference between the two languages is that Italian has low plurals; therefore it can employ plural as a massifier/collectivizer, determining gender switch. Sursilvan has high $-s$ plurals in Num; therefore massification/collectivization is obtained via non-plural morphology, again involving gender switch.

\section{The Albanian neuter}

\subsection{The structure of the Albanian $N$}

The traditional neuter of Albanian, briefly exemplified in (2) above, is in reality a mass nominal class. Standard Albanian no longer has a productive neuter class (Camaj 1984: §14), but Italo-Albanian (Arbëresh) varieties do. ${ }^{11}$ Before introducing the neuter, in (38)-(39) I present data relating to masculine and feminine Ns, both in the singular and in the plural. Though Albanian has a relatively rich case system, I exemplify only direct case (nominative) forms of $\mathrm{N}$, for which only gender, number and definiteness are relevant. In (38), when preceded by a demonstrative, Ns are in the indefinite form; in (39) they are in the definite form, which contributes definite reference to them. The left hand examples are masculine; the right hand ones are feminine.

(38) a. ai
that.MSG
kriatur
boy.MSG
kriatur-a
that.PL
boy-PL

b. ato

(39) a. kriatur-i

boy-MSG.DEF

'the boy'

b. kriatur-a-tə

boy-PL-DEF

'the boys'

$$
\begin{array}{ll}
\text { a'. ajo } & \text { vazd-ə } \\
\text { that.FSG } & \text { girl.FSG } \\
\text { b'. ato } & \text { vazd-a } \\
\text { that.PL } & \text { girl-PL }
\end{array}
$$

$$
\begin{aligned}
& \text { a'. vazd-a } \\
& \text { girl-FSG-DEF } \\
& \text { 'the girl' } \\
& \text { b'. vazd-a-tə } \\
& \text { girl-PL-DEF } \\
& \text { 'the girls' }
\end{aligned}
$$

11. These are independently documented, but non-standardized varieties, transcribed in a broad IPA from fieldwork sessions. Manzini \& Savoia (2018a) provide fuller data, including complete case paradigms and more inflectional classes. Specifically Manzini \& Savoia (2018a) provide a list of exponents paired with the contents they externalize. 
Let us begin by considering the indefinite Ns in (38). The masculine class (38a-b) alternates between the bare lexical base in the singular and the $-a$ inflection in the plural, while the feminine (38a'-b') alternates between /o/ and $-a$. The $-a$ vocalic plural is similar to the Italian ones, suggesting that $-a$ in the Infl position externalizes the [part] Class content. Thus, the indefinite singular burr has no Infl, as in (40a), while the indefinite plural burr- $a$ adds an Infl externalizing plurality as in (40b).

(40) a.

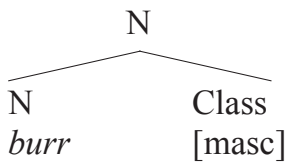

b.

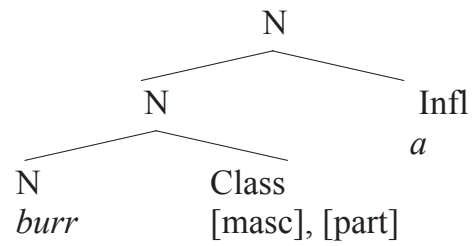

In the definite interpretation, Albanian Ns have a richer inflection. In the nominative singular, definiteness is conveyed by a segment specialized for gender as well as lack of number (at least in the masculine), namely $-i /-a$, as in (39a-a'). By contrast, definiteness is not overtly realized, as in (41).

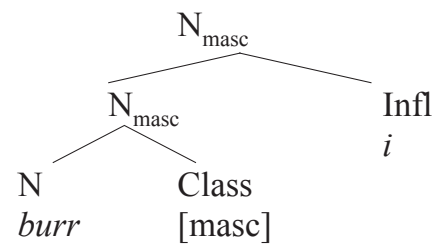

In the plural definite, the indefinite direct case form is followed by a - $t$ (a) segment, gender-independently, as in (39b-b'). The presence of definiteness specifications on nominal endings is an issue orthogonal to the present discussion, very much like case. Nevertheless, some model of it must be adopted in order to be able to proceed in the discussion. One possibility is that definite inflections such as $-t$ in (39b) are postnominal articles (e.g. Turano 2002). Manzini \& Savoia (2018a) offer an empirical argument against the head movement analysis, namely that Albanian definiteness inflections co-occur with prenominal articles at least with the class of kinship terms, requiring two different positions/categories to account for them. ${ }^{12}$ Therefore, they conclude that while prenominal articles are Ds, definiteness inflections are not. The alternative therefore is that $-t$ simply

12. The fact that Ds, when lexicalized, are prenominal, excludes that there is NP movement to Spec, DP. 
projects Num (and/or of Case, not considered here). The two alternatives, i.e. D and Num, are in any event notated in (42).

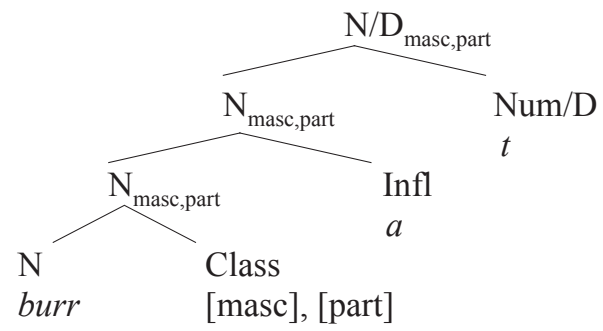

In short, $\mathrm{D}$ in Albanian is externalized by elements including demonstratives as well as quantifiers and the indefinite determiner. In this context, $\mathrm{N}$ has a poorer morphology, conventionally called indefinite, though of course there is nothing indefinite about a DP headed by a demonstrative as in (38). Definite expressions may be conceived in one of two ways. First they may consist of inflected Ns whose $\mathrm{D}$ position is not externalized. The latter nevertheless determines a richer inflection set on $\mathrm{N}$, including gender differentiation in the singular (nominative) or the $-t$ high number morphology in the plural. The alternative is to assume that they have a Ds - in which case this D must be sensitive to number as indicated by the alternation between zero and $-t$ in (39).

\subsection{The neuter: basic data and analysis}

With this much background, we can then proceed to consider the basic evidence concerning the so-called neuter gender, namely a nominal class reserved for mass terms. The data presented here relate to the varieties of Firmo, Civita. S. Benedetto Ullano (Cosenza). ${ }^{13}$ As shown in (43a), the direct case definite inflection is $-t$ as for the count plurals in (39). Importantly, the data in (43) show that the plural-like inflection of the neuter/mass noun is not a mere matter of morphological syncretism, since it triggers plural agreement in the syntax. Thus, the pre-adjectival Linker (Lkr) is $t \partial$, as in front of adjectives agreeing with a count plural.

(43) a. mif-t

meat-PL.DEF

'the meat'

b. bieita diat-t to barð

I.bought cheese- PL.DEF LKR.PL white

'I bought (the) white cheese'

13. There are some morphophonological alternations between the variety in (38)-(39) and the varieties in this section. They are syntactically irrelevant, e.g. - $t$ here vs. - $t$ o in (39). 
c. $\operatorname{dia} \theta-\mathrm{t} \quad \partial \int \mathrm{t}$ tə barð cheese-PL.DEF is LKR.PL white 'The cheese is white'

d. dia $\theta-\mathrm{t}$ jgə mə pərcen cheese-PL.DEF not to.me pleases

'I don't like cheese'

e. $\operatorname{dia} \theta-\mathrm{t} \quad \varepsilon$ ha pra

cheese-PL.DEF it I.eat after

'I eat the cheese afterwards'

In (44) the demonstrative is ata/kta, i.e. the form associated with count plurals - contrasting with the masculine/feminine singular demonstratives in (38). The linker is again in the plural form.

(44) a. a'ta $\operatorname{dia} \theta$

that.PL cheese

'that cheese'

b. k'ta mif oft to $\quad \mathrm{r} \varepsilon \mathrm{kt}$

this.PL meat is LKR.PL rotten

'This meat is rotten'

c. a'ta $\operatorname{dia} \theta \quad \partial \mathrm{ft}$ to $\operatorname{mir}$

that.PL cheese is LKR.PL good

'That cheese is good'

d. a'ta $\operatorname{dia} \theta \quad \varepsilon$ ha pra

that.PL cheese it I.eat after

'I eat that cheese afterwards'

While neuter/mass Ns agree in the plural within the DP, or in adjectival predication, they agree with the verb in the singular, as in (44b-c), (43c-d). Similarly, the resumptive clitic for the mass noun in (43e), (44d) is in the singular form $\varepsilon$. Singular agreement with the verb and with pronouns shows that neuter/mass terms are not simply pluralia tantum. More importantly, it evokes so-called hybrid nouns, analyzed by Wechsler \& Zlatic (2000) as a reflex of the existence of two sets of $\varphi$-features on $\mathrm{N}$ - namely Concord features and Index features. With hybrid nouns, Concord features typically govern DP-internal agreement and Index features govern pronominalization/ agreement with the finite verb, in accordance with Corbett's (1991) Agreement Hierarchy.

Recently, Landau (2016) proposes "a configurational adaptation of the CONCORD-INDEX distinction... Morphologically-rooted (=CONCORD) features are hosted on the noun stem while semantically-rooted (=INDEX) features are hosted on Num, a higher functional head". If we substitute $n /$ Class for N, the two positions envisaged by Landau are what I have called the low and the high 
number position so far. Furthermore, the configurational construal allows us to see more clearly the assumptions that are involved in accounting for hybrid nouns. The pivotal role is played by D, which ends up being a "hybrid head" to which both Concord and Index features are accessible. On the one hand, D can externalize Concord features, on the other hand it can agree in Index features with $v$ or $\mathrm{T}$ because those categories "lack Concord features".

The Albanian mixed agreement in (43)-(44) can certainly be accounted for in terms of Concord and Index features. We only need to assume that number is plural in the Concord set and singular in the Index set. However, from an interpretive point of view, the plural of count nouns and the singular of mass nouns corresponds to an underlying natural class, namely divisibility. A singular mass noun is like a plural count noun in that both include a multiplicity of some sorts namely a multiplicity of individuals, or a multiplicity of parts. In this perspective, it is far from obvious that Index features flow from the semantics of the so-called neuter - as opposed to Concord features. This specific objection highlights a more general issue with the Concord/Index approaches. Why would there be a Concord set of $\varphi$-features, morphologically realized and sensitive to syntactic Agree, which nevertheless don't do what $\varphi$-features interpretively do, i.e. track referential properties? If two different sets of features are present, then we expect them both to have some referential import.

As indicated in (22) above, Manzini \& Savoia (2018a) propose an [aggr] feature denoting mass divisibility to account for the so-called neuter of languages where the traditional neuter class is in reality a class of mass terms. I adopt the feature [aggr] to represent mass, which therefore is added to the number feature [part] responsible for plurality.

(45) a. [cheese] [aggr]

"there is an $\mathrm{x}$ such that $\mathrm{x}$ is a part of the whole "cheese",

b. [cheese/man] [part] $\rightarrow$

'there is an $\mathrm{x}$ such that $\mathrm{x}$ is a partition (part, subset) of 'cheese/"man',

Let us take the view that the mass/neuter nouns of Albanian are associated with [aggr] nominal class specifications. We can also assume that they are not associated with any gender. If the - $a$ Infl vowel of Albanian only selects gendered bases e.g. in (40b), we expect it to be absent on mass/neuter Ns, as in the indefinite (46).

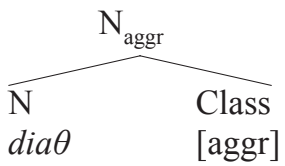

When the mass/neuter noun is definite, the same Num/D suffix - $t$ is present as on plural Ns. The unmarked assumption is that $-t$ is an externalization of [part] precisely as it is on burra- $t$ 'the men' in (42). This amounts to saying that Albanian mass/neuter Ns are associated with two numbers, namely [aggr] originating as a 
low number in Class and [part] originating as a high number in Num, as in (47). Importantly, these two numbers do not contradict one another and can be part of the same $\varphi$-feature set. Indeed, [part] subsumes [aggr] in its definition.

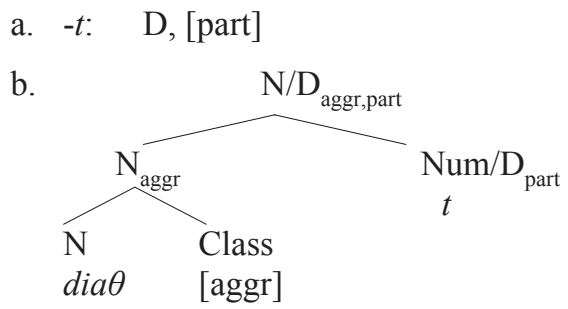

Plural and mass NPs behave identically under DP-internal Agree, for instance between $\mathrm{N}$ and $\mathrm{A}$ in (43c). This application of Agree affects the preadjectival Lkr, which has the same to morphology as the postnominal $-t$ inflection in (47). In (48), I have adopted the analysis of linkers under which they are Ds (e.g. Lekakou \& Zsendroi 2012). Agree is with respect to the feature [part].

$$
\left[{ } _ { \mathrm { NP } } \operatorname { d i a } \theta t _ { [ \text { [aggr,part] } } \cdots \quad \left[\left[_{\mathrm{DP}} \partial_{[\text {part }]} \quad\left[\left[_{\mathrm{AP}} \text { bard] }\right]\right] \quad=(43 \mathrm{c})\right.\right.\right.
$$

Next, demonstratives and other Ds merging with indefinite Ns have the same form as in the plural, because again I assume that the noun and its determiners agree with respect to the property [part], as in (49)..$^{14}$ The easiest technical implementation of this assumption is that indefinite Ns have a further Num layer (though morphologically unrealized) with respect to (46), so that they present the same [part], [aggr] cluster as definite Ns under Agree.

$$
\left[{ }_{\mathrm{DP}} a t a_{[\text {part }]} \quad\left[_{\mathrm{NP}} \operatorname{dia} \theta_{[\text {aggr,part] }}\right]\right]
$$

Despite the presence of pervasive plural morphology on the noun, its determiners and its modifiers, agreement with the finite verb or with clitic pronouns is in the singular. ${ }^{15} \mathrm{I}$ must therefore assume that contrary to $\mathrm{N}$ morphology and DP-internal Agree, which are sensitive to [part], pronouns and verb inflections are sensitive to [aggr]. This is externalized as the (default) singular, in (50).

$$
\left[{ }_{\mathrm{NP}} d i a \theta t_{\text {aggr,part }} \quad\left[\mathrm{IP}_{\mathrm{IP}} \partial f t \quad\left[{ }_{\mathrm{DP}} t_{[\mathrm{part}]} \text { bard] }\right]\right] \quad=(43 \mathrm{c})\right.
$$

14. The - $a$ morphology on the demonstrative does not coincide with the Infl morphology seen on Ns, because demonstrative/pronominal $-a$ is stressed (and $\mathrm{N}$-internal $-a$ is unstressed).

15. The participle is only present in the middle-passive voice, as in Latin or Greek and does not change the picture in the text. The verbal participle is a non-agreeing form, as in English. The adjectival participle has the same agreement properties of any adjective, see Manzini \& Savoia (2018a) and references quoted there. 
In (50), I assume that the agreement with [part] within the DP is a partial agreement, made possible by the fact that the complete feature set [aggr], [part] is carried by $\mathrm{N}$ and labels the DP. Agreement with sentential heads (pronouns, verb agreement) is with the full feature set [aggr], [part]. The result is failure with respect to [aggr] and therefore default number, i.e. singular, kicks in. ${ }^{16}$

Summing up, the present treatment follows Concord/Index models of agreement, in assuming that the mixed agreement properties of Albanian mass/neuter Ns depends on the presence of two different number specifications. In keeping with the configurational construal of Index/Concord Agree introduced by Landau (2016), the two number specifications are merged in Class and Num. Nevertheless, I also introduce some new proposals. First, the two number features are not incompatible, so that both of them are interpreted. As a consequence, though there are two number features, there is a single $\varphi$-feature set encompassing them.

A final question is whether Albanian neuter Ns are truly forced to have an [aggr] reading - or can also be coerced into a count reading. As the literature on the count/ mass distinction emphasizes (Borer 2005 and references quoted there), in English and in many other languages, count nouns can be coerced into a mass interpretation (the so-called universal grinder effect) and mass nouns can be coerced into a count syntax, typically yielding interpretations such 'unit of', 'type of'. The switch from mass to count denotation depends entirely on syntactic context and does not imply any difference in the nominal class, inflectional class or number associated with the lexical base.

In Albanian, however, lexical bases like dia $\theta$ 'cheese' have different inflectional and agreement properties under the count reading. Thus, dia $\theta$ with a count interpretation has the ordinary [masc] singular declension, as in (51). The nominative singular definite form dia $\theta-i$ 'the cheese' with count interpretation in (51) exactly parallels that of burr-i 'the man' in (41).

(51) $\operatorname{dia} \theta-\mathrm{i}$

cheese-M.DEF

'the block/wheel of cheese'

In turn, the count plural of lexical bases like dia $\theta$ 'cheese' is formed by enlarging the lexical base with an - $\partial r$ - affix, which is followed by the regular dia $\theta$ 'cheese' count plural inflection $-a-t$, as in in (52). In (52), - $\partial r$ - is not a singulative added to the mass base. Rather (52) is the plural of the count form in (51). Indeed, plurals

16. Crosslinguistically, mixed agreement is a possible, not a necessary outcome. Subject-verb agreement involving the Arabic broken (low) plurals can in principle be in the singular or in the plural. According to Dali and Mathieu (2016) agreement in the plural implies the same readings as in English, i.e. either a single event with multiple participants or multiple events, each with one or more participants. Subject-verb agreement in the singular forces the single event reading, as illustrated in (i) for Tunisian Arabic.

(i) El rjel xerj-u wehed wehed/ xerj-et (*wehed wehed)

DEF man.PL exited-M.PL one one/ exited-F.SG one one

'The men went out (one by one)'

Tunisian Arabic 
with the - $\partial r$ - extension characterize an entire subclass of masculine count nouns, e.g. $a / t-i / \varepsilon f t-\partial r-a t$ 'the bone/the bones', $f i / t-i / f i / t-\partial r-a t$ 'the finger/the fingers' ${ }^{17}$

(52) a
a. dia $\theta-\partial r-a t / \quad$ mif-ər-at
cheese-PL-PL.DEF/ meat-PL-PL.DEF
'the cheeses/meats'
b. dia $\theta$-ər-at jan to Jkalmuar-a
cheese-PL-PL.DEF are LKR.PL spoiled-PL
'The cheeses are spoiled'

In other words, no count construals of the neuter/mass Ns in (43)-(44) are possible - confirming the present analysis of them as a dedicated mass class.

\subsection{Interaction with gender}

A potentially interesting question is whether the low number feature [aggr] that I have postulated for the Albanian neuter/mass class can trigger its own gender - like other low plurals. I return to this question at the end of this section, after reviewing the interaction of [aggr] with gender more generally.

In addition to direct/nominative case, Albanian has an oblique case, encompassing genitive and dative. Baldi \& Savoia (2018) document at least one variety, namely Greci, where nouns of the mass/neuter class have plural-like inflections and DP-internal plural agreement not only in the direct case, but also in the oblique, as illustrated in (53).

Greci (Avellino)

However it is more frequent to find that in the oblique case, neuter/mass lexical bases are inflected in the masculine singular and also agree in the masculine singular, as in (54). Evidently, in most varieties, the [aggr] class triggering [part] inflections and agreement within the DP only has direct cases. The forms of the oblique in (54) are suppletive, namely they are provided by the [masc] declension of the same lexical bases, as in (51) above.

17. The suffix - $\partial r$ - for plural formation is a loan from Romance varieties, where it is followed by the $-a$ plural inflection, e.g. Old Florentine/Old Italian camp-or- $a$ 'fields' (standard Italian camp- $i$ 'fields'). Therefore, it is not a surprise that the Arbëresh -ər-plural class overlaps with the Italian - $a$ plural class. 
(54) a. sapur-i i dia $\theta-\mathrm{i}-\mathrm{t}$

taste-MSG.DEF LKR.MSG cheese-MSG-OBL.DEF

'the taste of the cheese'
b. sapur-i
ktij $\operatorname{mia} \Lambda-\mathrm{i}$
'the taste of this honey'

There are also mass bases displaying [fem] properties, for instance ver 'wine'. These agree with demonstratives in the plural, as seen in the form of the demonstrative ata in (55b). At the same time, these nouns follow the [fem] declension in the definite forms, as indicated by the inflections $-a$ (nominative) in (55a) and - $2 n$ (accusative) in (55b). Linkers in (55a) alternate between plural to and feminine $\varepsilon$.
b. a $m$ ver-ə-n/ a'ta ver give me wine-FSG-ACC.DEF/ that wine 'Give me the wine/that wine'

In essence, Ns like $v \varepsilon r$ 'wine' display the pattern expected of mass/neuter Ns in the indefinite (55b), where they cooccur with plural-like determiners. Therefore in the indefinite, we may assume that an [aggr] lexical base is involved. In the definite declension, the inflectional endings and also the form of the agreeing linkers seems to indicate that a [fem] lexical base is involved. In other words, this pattern may be dealt with as involving two slightly different allomorphs of the lexical base.

With this much background, we can return to the question that directly concerns us here, namely whether there is any evidence that the [aggr] class can determine its own gender. Baldi \& Savoia (2018) document peripheral varieties in which mass/ neuter Ns have plural-like inflections, namely definite -to in (56b-c). However, they agree with determiners and modifiers in the feminine singular.
(56) a. aj-o mifo iftə $\varepsilon \quad$ cerbərə
that-FSG meat is LKR.FSG rotten
'That meat is rotten'
b. mə pərcekətə mif-tə
me pleases meat-PL.DEF
'I like the water/meat/honey'
c. ujə-tə ift $\varepsilon$ ygroyərə
water-PL.DEF is LKR.FSG hot
'The water is hot'


In present terms, the mass/neuter Ns in (56) can be described as having [aggr] in Class and [part] in Num, triggering the -to definite inflection. However [aggr] selects its own [fem] gender. Agreement is then governed by [fem], [aggr], i.e. feminine singular. ${ }^{18}$

In short, the Albanian neuter/mass class involves a restricted number of lexical bases, associated with mass meaning, displaying plural agreement within the DP but singular agreement with the finite verb, and finally marginally capable of triggering their own gender. The present proposal is that all of these properties are connected to the presence of a low number specification, namely [aggr].

\section{Conclusions}

Italian - $a$ plurals and the Albanian mass neuter bring evidence to bear on the issue whether number is merged in Class (low number) as well as in Num (high number) and on whether low and high number differ in their syntactic and interpretive properties. Specifically, low number is associated with idiosyncratic meanings, interaction with gender and mixed agreement. Interaction with gender characterizes the $-a$ plural of Italian, while mixed agreement characterizes the Albanian mass neuter, also connecting it to the more general issue of Concord (low) vs Index (high) features. The parallelism with other languages families, notably the AfroAsiatic one, hints at the conclusion that the deep syntactico-semantic organization of number and class categories is involved.

In general, inflectional systems face the linguist with the classical problem how best to represent syncretisms. Syncretism of mass and plural inflections in Albanian is the reflex of a more primitive contrast between non-atomic, aggregate content (mass, plural) and atomic (count singular) denotation captured here by [part] (partition or divisibility). I have proposed that the same superclass [part] is involved in Italian - $a$ plurals. Merger of the traditionally separate categories of gender and number under the same Class node is a further, theoretically relevant aspect of the analysis. Specifically, I have argued that the so-called neuter in Albanian varieties involves coding of mass number, [aggr], in the lower Class node.

18. In the variety in (i)-(ii), mass/neuter Ns have plural-like inflections, namely definite -to in (i), and they agree with determiners and modifiers in the masculine singular (ii). The distribution of gender and number features is the same as in (56) except that the gender is [masc], determined by the lexical base.

(i) dia $\theta \partial-$ tə cheese-PL.DEF 'the cheese'

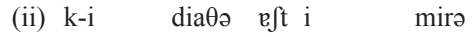

this-MSG cheese is LKR.MSG good 'This cheese is good' 


\section{References}

Acquaviva, P. 2008. Lexical Plurals. Oxford: Oxford University Press.

Arsenijević, B. 2006. Partitivity and Reference. In J. Dotlacil \& B. Gehrke (eds.). Proceedings of the second Syntax AiO Meeting, 48-64.

Arsenijević, B. 2016. Gender, like Classifiers, Marks Uniform Atomicity: Evidence from Serbo-Croatian. Chicago Linguistic Society 52: 21-23.

Baker, M. 1988. Incorporation: A Theory of Grammatical Function Changing. Chicago: University of Chicago Press.

Baldi, B. \& Savoia, L. M. 2018. Morphosyntactic Reorganization Phenomena in Arbëresh Dialects: The Neuter. Quaderni di Linguistica e Studi Orientali 4: 109-130.

$<$ http://dx.doi.org/10.13128/QULSO-2421-7220-23841>

Bonet, E. 2018. Missing Inflectional Features and Missing Exponents in DP-Internal Agreement Asymmetries. Glossa: A Journal of General Linguistics 3(1): 1-19. $<$ https://doi.org/10.5334/gjgl.579>

Borer, H. 2005. Structuring Sense, Vol. 1: In Name Only. Oxford: Oxford University Press.

Brody, M. 2000. Mirror Theory: Syntactic Representation in Perfect Syntax. Linguistic Inquiry 31(1): 29-56.

Calabrese, A. 1998. Some Remarks on the Latin Case System and Its Development in Romance. In J. Lema \& E. Trevino (eds.). Theoretical Advances on Romance Languages, 71-126. Amsterdam: John Benjamins.

Camaj, M. 1984. Albanian Grammar. Wiesbaden: Harrassowitz.

Carstens, V. 2000. Concord in Minimalist Theory. Linguistic Inquiry 31(2): 319-355.

Chierchia, G. 2010. Mass Nouns, Vagueness and Semantic Variation. Synthese 174: 99-149.

Chomsky, N. 1995. The Minimalist Program. Cambridge, MA: MIT Press.

Chomsky, N. 2000. Minimalist Inquiries: The Framework. In R. Martin, D. Michaels \& J. Uriagereka (eds.). Step by Step, Essays on Minimalist Syntax in Honor of Howard Lasnik, 89-155. Cambridge, MA: MIT Press.

Chomsky, N. 2001. Derivation by Phase. In M. Kenstowicz (ed.). Ken Hale: A Life in Language, 1-54. Cambridge, Mass: The MIT Press.

Corbett, G. 1991. Gender. Cambridge: Cambridge University Press.

Dali, M. \& Mathieu, E. 2016. Les pluriels internes féminins de l'arabe tunisien. Lingvisticae Investigationes 39(2): 253-271.

$<$ https://doi.org/10.1075/li.39.2.03dal $>$

Danon, G. 2010. Agreement and DP-Internal Feature Distribution. Syntax 14: 297-319.

Déchaine, R.-M., Girard, R., Mudzingwa, C. \& Wiltschko, M. 2014. The Internal Syntax of Shona Class Prefixes. Language Sciences 43: 18-46.

Fassi Fehri, A. 2012. Key Features and Parameters in Arabic Grammar. Amsterdam: John Benjamins.

Fassi Fehri, A. 2018. Constructing Feminine to Mean. Lanham: Lexington Books.

Ferrari Bridgers, F. 2008. A Unified Syntactic Analysis of Italian and Luganda Nouns. In C. De Cat \& K. Demuth (eds.). The Bantu-Romance Connection, 239-260. Amsterdam: John Benjamins. 
Halle, M. \& Marantz, A. 1993. Distributed Morphology and the Pieces of Inflection. In K. Hale \& S. J. Keyser (eds.). The View from Building 20, 111-176. Cambridge, Mass: MIT Press.

Halle, M. \& Vaux, B. 1998. Theoretical Aspects of Indo-European Nominal Morphology: The Nominal Declensions of Latin and Armenian. In J. Jasanoff, H. C. Melchert \& L. Oliver (eds.). Mir Curad: Studies in Honor of Calvert Watkins, 223-240. Innsbruck: Innsbrucker Beitraege zur Sprachwissenschaft.

Harris, J. 1991. The Exponence of Gender in Spanish. Linguistic Inquiry 22: 27-62.

Higginbotham, J. 1985. On Semantics. Linguistic Inquiry 16: 547-621.

Kayne, R. 2010. Comparisons and Contrasts. New York: Oxford University Press.

Kramer, R. 2015. The Morphosyntax of Gender. Oxford: Oxford University Press.

Kramer, R. 2016. A Split Analysis of Plurality: Number in Amharic. Linguistic Inquiry 47(3): 527-559.

Kučerova, I. 2018. $\phi$-Features at the Syntax-Semantics Interface: Evidence from Nominal Inflection. Linguistic Inquiry 49: 813-845.

Lahrouchi, M. \& Lampitelli, N. 2015. On Plurals, Noun Phrase and Num(ber) in Moroccan Arabic and Djibouti Somali. In N. Lampitelli et al. (eds.). The Form of Structure, the Structure of Form: Essays in Honor of Jean Lowenstamm, 303-314. Amsterdam: Benjamins.

Lampitelli, N. 2014. The Romance Plural Isogloss and Linguistic Change: A Comparative Study of Romance Nouns. Lingua 140: 158-179.

Landau, I. 2016. DP-Internal Semantic Agreement: A Configurational Analysis. Natural Language and Linguistic Theory 34: 975-1020.

Lecarme, J. 2002. Gender "Polarity": Theoretical Aspects of Somali Nominal Morphology. In P. Boucher \& M. Plénat (eds.). Many Morphologies, 109-141. Somerville, Massachusetts: Cascadilla Press.

Lekakou, M. \& Szendrői, K. 2012. Polydefinites in Greek: Ellipsis, Close Apposition and Expletive Determiners. Journal of Linguistics 48: 107-149.

Loporcaro, M. \& Paciaroni, T. 2011. Four Gender-Systems in Indo-European. Folia Linguistica XLV: 389-433.

Manzini, M. R. \& Savoia, L. M. 2017. Gender, Number and Inflectional Class in Romance: Feminine/Plural - $a$. In J. Emonds \& M. Janebova (eds.). Language Use and Linguistic Structure, 263-282. Olomouc: Palacky University Olomouc.

Manzini, M. R. \& Savoia, L. M. 2018a. The Morphosyntax of Albanian and Aromanian Varieties. Berlin: Mouton de Gruyte

Manzini, M. R. \& Savoia, L. M. 2018b. N Inflections and Their Interpretation: Neuter $-o$ and Plural $-a$ in Italian Varieties. In R. Petrosino, P. Cerrone \& H. van der Hulst (eds.). From Sounds to Structures: Beyond the Veil of Maya, 361-394. Berlin: Mouton De Gruyter.

Manzini, M. R. \& Savoia, L. M. 2019. N Morphology and Its Interpretation. Romance Feminine Singular/Plural - $a$. In S. Cruschina, A. Ledgeway \& E.-M. Remberger. Italian Dialectology at the Interfaces, 257-293. Amsterdam: John Benjamins.

Marantz, A. 1997. No Escape from Syntax: Don't try Morphological Analysis in the Privacy of Your Own Lexicon. University of Pennsylvania Working Papers in Linguistics 4: 201-225.

Oltra-Massuet, I. \& Arregi, K. 2005. Stress-by-Structure in Spanish. Linguistic Inquiry 36(1): 43-84. 
Percus, O. 2011. Gender Features and Interpretation: A Case Study. Morphology 21: 167-196.

Picallo, C. 2008. Gender and Number in Romance. Lingue e Linguaggio VII: 47-66.

Preminger, O. 2014. Agreement and Its Failures. Cambridge, MA: The MIT Press.

Rijkhoff, J. 1991. Nominal Aspect. Journal of Semantics 8(4): 291-309.

Savoia, L., Baldi, B., Franco, L. \& Manzini, M. R. 2017. Nominal Evaluative Suffixes in Italian. In R. D’Alessandro, G. Iannàccaro, D. Passino \& A. Thornton (eds.). Di tutti $i$ colori [Studi linguistici per Maria Grossmann]. Utrecht University Repository

Savoia, L., Baldi, B. \& Manzini, M. R. 2018. Sigmatic Plurals in Romance Varieties Spoken in Italy and Their Interaction with $-i$ Plurals. LINGBAW 4: 141-160.

Thornton, A. 2010-11. La non canonicità del tipo it. braccio // braccia / bracci: sovrabbondanza, difettività o iperdifferenziazione? Studi di grammatica Italiana 29-30: 419-477.

Tsoulas, G. 2009. On the Grammar of Number and Mass Terms in Greek. Proceedings of the 2007 Workshop in Greek Syntax and Semantics. MIT Working Papers in Linguistics 56, 131-146.

Turano, G. 2002. On Modifiers Preceded by the Article in Albanian DPs. University of Venice Working Papers in Linguistics 12: 169-215.

Wechsler, S. \& Zlatić, L. 2000. A Theory of Agreement and Its Application to SerboCroatian. Language 76(4): 799-832.

Wiltschko, M. 2008. The Syntax of Non-inflectional Plural Marking. Natural Language and Linguistic Theory 26: 639-694. 